\title{
Assessment of the Muscle Strength and Range of Motion Ankle in Boys With and Without Flatfoot
}

\author{
Kasbparast Mehdi*, Rahimi Alireza, Shokrgozar Alireza and Aghaie Fariba \\ Department of Sport Injury and Biomechanics, Islamic Azad University, Iran
}

*Corresponding author: Kasbparast Mehdi, Department of Sport Injury and Biomechanics, Faculty of Physical Education and Sport Sciences, Islamic Azad University, Karaj Branch, Alborz, Iran

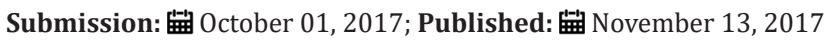

\begin{abstract}
The purpose of the present survey is the comparison of the strength and range of motion of ankles' muscles in teenager boys with and without flatfoot. For this purpose, 50 subjects consisted of 25 students who had flexible flat foot, with a mean age, height and weight, $12 \pm 0.87$ years, $149.84 \pm 9.71 \mathrm{~cm}$, $45.92 \pm 10.58 \mathrm{~kg}$ respectively, and 25 students without flatfoot with a mean age, height and weight, $11.92 \pm 0.81$ years, $150.88 \pm 8.21 \mathrm{~cm}$ and $46.28 \pm 9.34 \mathrm{~kg}$ respectively, participated in the research after medical examination by the physician. The comparison of the strength of ankle's muscles in D.F and P.F, and the ankles' range of motion in dorsiflexion and plantarflexion was evaluated in three conditions of without resistance, under pressure, and with resistance in both healthy and affected groups. Clear universal goniometer was used for measuring the range of motion. Lafayette hand-held digital dynamometer was used for measuring the strength. All the data was evaluated through SPSS software version 20. Alpha 0.05 was regarded as the level of significance. Independent $t$-test was used for comparing the aforementioned variables in two groups. To compare the range of motion in D.F and P.F in three evaluating conditions for each of the motions one inter group variable of measurement condition (including 3 levels) and one intra group variable was used based on separated variance analysis. Multiple analysis of variance test and one-way analysis of variance (ANOVA) with Bonferroni correction was used. The present investigation showed that no significant difference was seen between the aforesaid hypotheses among two healthy and flat foot affected groups.
\end{abstract}

Keywords: Flat foot; Isometric strength; Range of motion

\section{Introduction}

The ankle joint is formed by the articulation between the mortise of the lower tibia and fibula and the trochlear surface of the talus. Actually composed of 3 joints the tibiotalar, tibiofibular and fibulotalar joints [1], it plays an essential role during walking, and is of great importance during physical activities [2]. It is generally believed that the upward and downward movement of the foot, referred to as dorsiflexion (D.F) and plantarflexion (P.F), respectively, occurs mainly at this joint [2,3]. This Tibiotalar movement involves the rotation of the talus within the ankle mortise [4], with un-resisted mobility being obtained by the sliding of the articular surfaces upon each other [5]. The ankle range of motion for D.F and P.F showed in Figure 1. Ankle plantarflexor strength (force-generating capacity of muscle) has an important role in standing balance, walking ability, and most activities of daily living [6-8]. During walking, the plantar flexors slow down the forward motion of the tibia over the foot during the stance phase and propel the body forward during push-off. People with weak plantar flexors usually present a crouch gait pattern during walking, difficulty in performing activities involving lower limbs or even inability to perform such activities, or inadequate standing balance. For patients displaying these signs, examination of plantar-flexor strength is prudent $[9,10]$. In the ankle joint, while the muscles carry on the responsibility of producing the maximal muscle power and the peak moment when the foot contacts the ground at mid foot strike; they are also responsible for positioning the foot in plantar flexion and inversion [11-14]. This provides shortening in the duration of the support phase for faster forward acceleration and decreases the contact time for less friction between the foot and the ground $[14,15]$. The antagonistic dorsiflexors and evertors are eccentrically contracting to control the concentrically contracted plantar flexors and invertors [16]. The flexibility and the strength of the muscles are important for this co-contraction of the muscle groups to prepare the foot for push-off; the other hand, the leg muscles and the non-contractile tissues must also be flexible enough to store the elastic energy in the pre-stretched antagonists [14].

Range of motion of the ankle, or any joint, is the measurable amount of movement in the joint. The standard range of motion for D.F is between 15 and 30 degrees. For P.F, the typical range of motion is between 20 and 50 degrees. These ranges vary according to age, gender and muscle strength. The objective and subjective clinical assessment of flexible flatfoot is an important step in determining an accurate diagnosis. Without an appropriate checklist for diagnosis, the presence of flatfoot and the related clinical aspects 
can be over- or underestimated. Consequently, unnecessary or inadequate treatment may be undertaken. Childhood flexible flat foot is the most common condition of the lower limb [17], in which the medial longitudinal arch of the foot collapses during weight bearing and restores after removal of body weight [18-20]. The true prevalence of flatfoot is unknown, primarily because there is no consensus on the strict clinical or radiographic criteria for defining a flatfoot [21]. But some authors reported that the prevalence of flexible flatfoot in children, (2 to 6 years of age) is between $21 \%$ and $57 \%$, and the percentage has decreased to $13.4 \%$ and $27.6 \%$ in primary school children [22,23]. Many individuals with flexible flatfeet walk with certain alterations in the lower extremity kinematics. The most common alteration is excessive pronation of the subtalar joint during stance phase [24-27]. In normal gait, the subtalar joint start to pronate after initial contact until the metatarsal head contacts the ground, where upon the subtalar joint starts to supinate and converts the foot into a rigid structure for propulsion in the late stance phase $[28,29]$. In people with flexible flatfeet, the foot stays in a pronated position without turning to supination early enough during the late stance phase [30], which is not efficient for completing the push-off during gait [28,31,32]. Although flexible flatfoot in children rarely causes pain or disability, Lin et al. suggested that kinematic changes and the resulting gait deviations may lead to lower extremity pathologies later in life [24]. A study reported that the diagnosis of flexible flatfoot is an exclusion diagnosis, based on the static morphology and radiographs of the foot [33]. Also, reported that diagnosis of hyper mobile flatfoot should include $>1$ of the following signs: forefoot abduction, forefoot supination, and heel valgus [34]. flexible flatfoot diagnosis cannot merely rely on a morphologic assessment but should be defined functionally as a foot that, on weight bearing, stays in a state of prevalent or persistent pronation [3], and for which abnormal foot biomechanics could result in fatigue and overuse syndromes over time [33]. Thus, the evaluation of flatfoot should include a combination of measures and tests besides morphology that assess the foot's dynamic status [35].

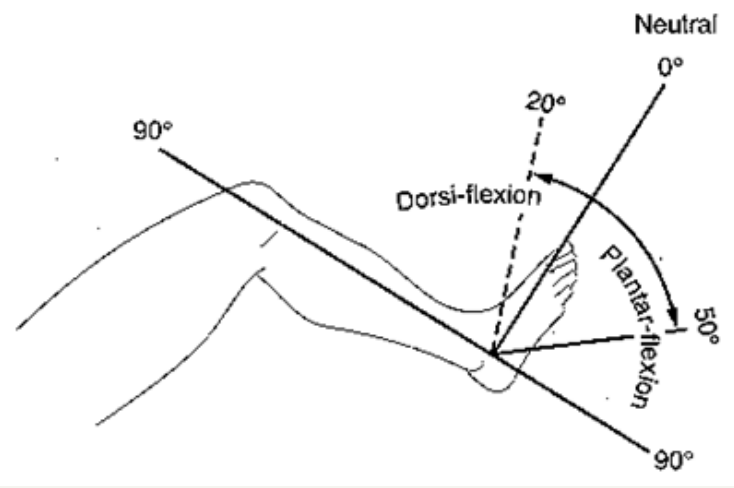

Figure 1: Ankle joint motions.

\section{Materials and Methods}

First of all 50 students were selected with and without flat foot, (25 people in each group). 25 students who had flexible flat foot, with a mean age, height and weight, $12 \pm 0.87,149.84 \pm 9.71$, $45.92 \pm 10.58$ respectively and 25 students without flatfoot with a mean age, height and weight $11.92 \pm 0.81,150.88 \pm 8.21$ and $46.28 \pm 9.34$ respectively that they participated in the research after medical examination by the physician and via pedscope and fallen arches. All of patients were with acquired and grade 1 flexible flatfoot. To measure the ankle muscle strength in subjects, we performed two methods: A. to measure of plantarflexor muscle strength, Subjects to lie on your stomach on the bed and his knee was in extension and neutral for ankle. Then subjects applied strength with isometric contraction on the dynamometer for 5 seconds. B. to measure of plantar flexor muscle strength, the subjects were lying back on the bed and his knee was in extension and neutral for ankle. Then subjects applied strength with isometric contraction on the dynamometer for 5 seconds. The strength of ankle muscles measured via hand-held digital dynamometer. Each patient does the isometric contraction with maximum strength and keeps it for 5 seconds in dorsiflexion and plantarflexion separately. Also, ankles' range of motion measured via goniometer in three positions: A. neutral. B. Plantarflexion and C. Dorsiflexion. The ankles' range of motion in dorsiflexion was evaluated also in three conditions of without resistance, under pressure, and with resistance in both healthy and affected groups (Figure 2-8).

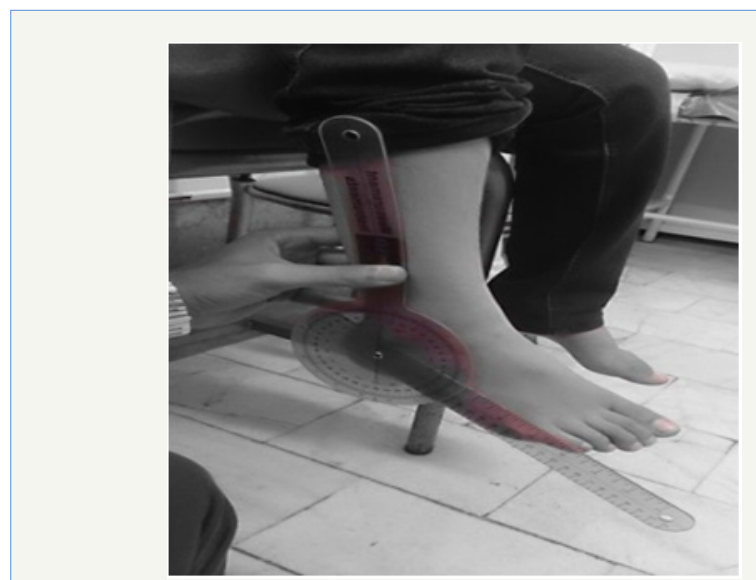

Figure 2: Neutral position.

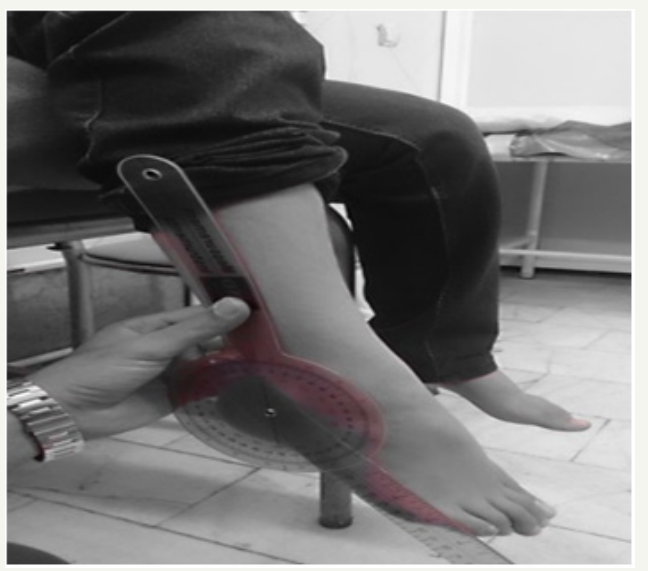

Figure 3: Plantarfelexion position. 


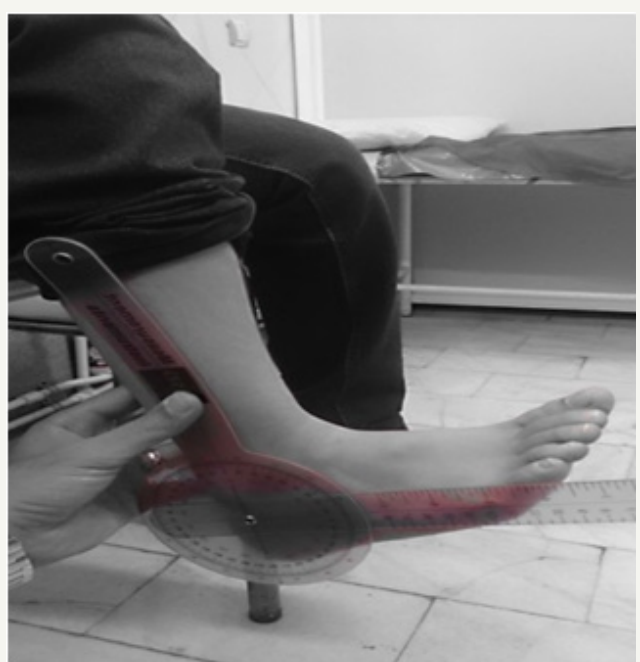

Figure 4: Dorsiflexion position.

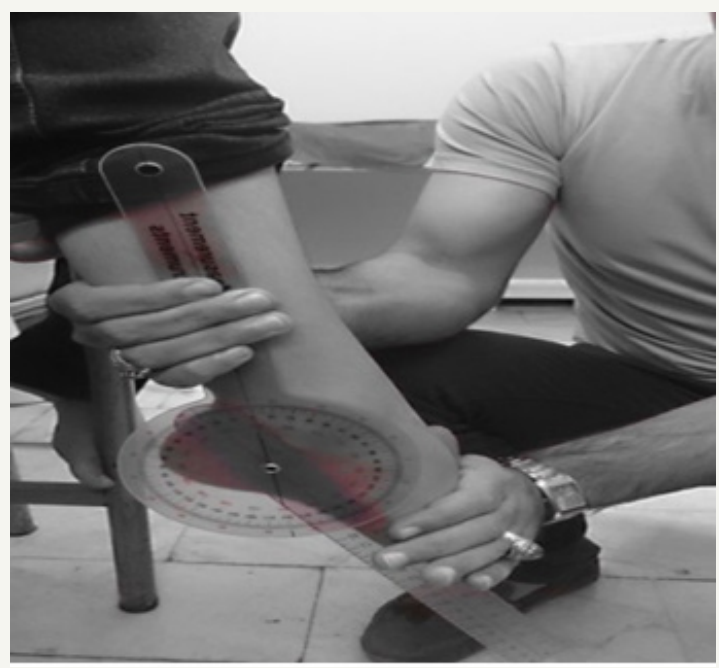

Figure 5: P.F under pressure.

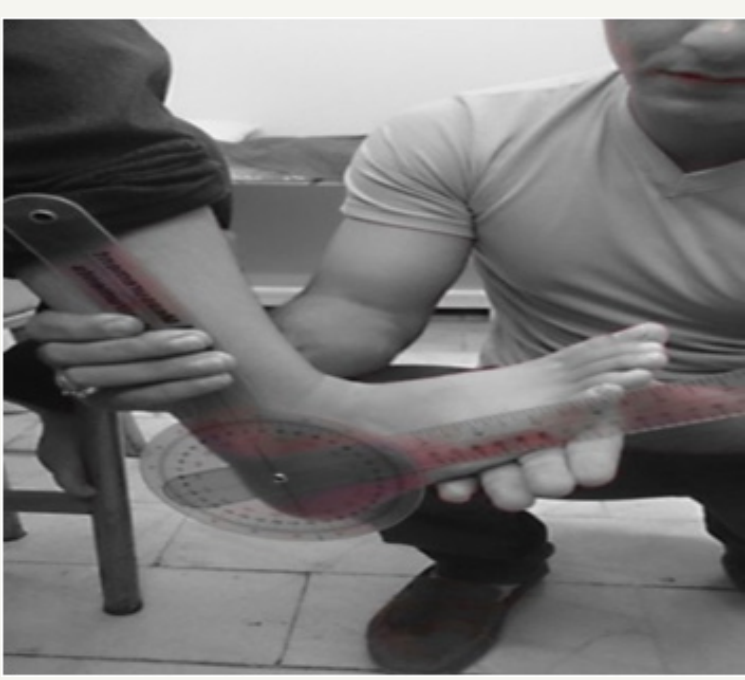

Figure 6: D.F under pressure.

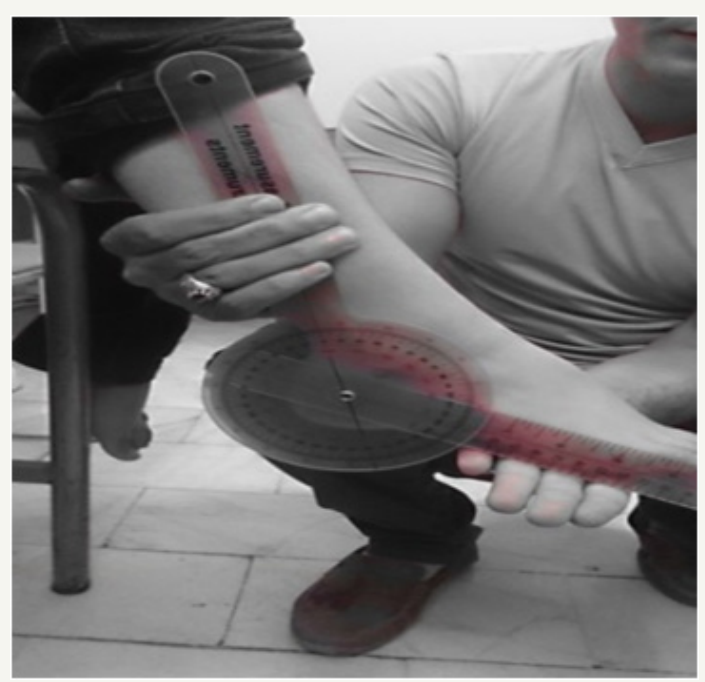

Figure 7: P.F. with resistance.

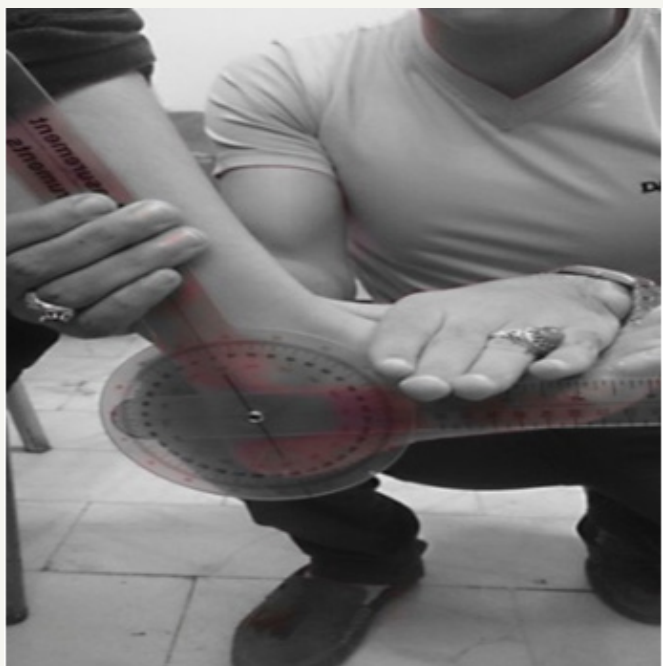

Figure 8: D.F. with resistance.

\section{Results}

Table 1: The range of motion in dorsiflexion and plantarflexion without resistance, under pressure and with resistance among persons with and without flatfoot.

\begin{tabular}{|c|c|c|c|}
\hline \multirow{2}{*}{ ROM } & \multirow{2}{*}{ Measurement } & \multicolumn{2}{|c|}{ Group } \\
\hline & & Flatfoot & $\begin{array}{l}\text { Without } \\
\text { Flatfoot }\end{array}$ \\
\hline $\begin{array}{l}\text { Without } \\
\text { resistance }\end{array}$ & \multirow{3}{*}{$\begin{array}{l}\text { ROM of Dorsiflexion } \\
\text { (Degree) }\end{array}$} & $41.28 \pm 8.17$ & $43.40 \pm 8.10$ \\
\hline Under pressure & & $50.16 \pm 9.26$ & $52.92 \pm 10.04$ \\
\hline With resistance & & $24.16 \pm 8.97$ & $30.40 \pm 10.16$ \\
\hline $\begin{array}{l}\text { Without } \\
\text { resistance }\end{array}$ & \multirow{3}{*}{$\begin{array}{l}\text { ROM of Plantarflexion } \\
\text { (Degree) }\end{array}$} & $22.68 \pm 9.11$ & $24.16 \pm 8.97$ \\
\hline Under pressure & & $31.04 \pm 10.86$ & $32.64 \pm 8.79$ \\
\hline With resistance & & $14.20 \pm 7.35$ & $15.84 \pm 6.65$ \\
\hline
\end{tabular}


Table 2: The strength and Ratio of Dorsiflexors and Plantarflexors muscle among persons with and without Flatfoot.

\begin{tabular}{|c|c|c|}
\hline \multirow{2}{*}{ Variable } & \multicolumn{2}{|c|}{ Group } \\
\cline { 2 - 3 } & Flatfoot & Without Flatfoot \\
\hline Dorsiflexion strength $(\mathrm{Kg} / \mathrm{BW})$ & $0.12 \pm 0.04$ & $0.13 \pm 0.04$ \\
\hline Plantarflexion strength (Kg/BW) & $0.26 \pm 0.11$ & $0.26 \pm 0.08$ \\
\hline $\begin{array}{c}\text { Plantarflexion to Dorsiflexion } \\
\text { strength Ratio }\end{array}$ & $2.32 \pm 0.97$ & $2.06 \pm 0.68$ \\
\hline
\end{tabular}

The summery of our results indicated in Table $1 \& 2$. There is no significant different in the range of motion in P.F among subjects with and without flat foot but results also indicated range of motion in under pressure position was more than without resistance and with resistance, significantly. Also range of motion without resistance was more than range of motion in with resistance position. Muscle strength of D.F and P.F do not showed significant different among students with and without flatfoot. Of course, dorsiflexor muscles strength are less than plantarflexor muscle strength. It is justified anatomically. In addition, our results indicate that there is no significant different between plantarflexors muscle strength in flatfoot and without flatfoot persons.

\section{Discussion and Conclusion}

The objective and subjective clinical assessment of flexible flatfoot is an important step in determining an accurate diagnosis. Without an appropriate checklist for diagnosis, the presence of flatfoot and the related clinical aspects can be over- or underestimated. The objectives of this study were to Comparison of the strength and range of motion of ankles' muscles in teenager boys with and without flatfoot. Our results indicated that there are no statistically significant differences between strength and range of motion in ankle among patients with flatfoot and healthy foot. It is different with some studies $[36,37]$. The reason for the discrepancy between the present results and other studies probably is sexuality, while the strength loss is higher in women than men.

Also one possible reason for the difference is the age range of subjects, because age is one of the important factors for strength. Many previous studies have assessed age-related declines in absolute strength by using measurements of isometric and/or concentric force production [38-40]. A few studies have examined changes in eccentric strength with age. The method used in this study, try to the effect of other muscle strength to be minimized, because evaluation of the large muscle groups in the individuals stronger is harder. The muscle groups of the lower extremities are strong so, sufficient stability for lower extremity is required during clinical evaluation. In some studies, dynamometer fixed by hand and in most cases, a tester was strong, skilled and experienced in the use of hand-held dynamometer. [26,41,42]. In present study for more stability of the lower extremity, strap was used. Also the second examiner also has features such as skill, ability and experience in the use of hand-held dynamometer was used. Reduced ankle dorsiflexion was correlated with age and probably due to Achilles tendon shortening [43]. The correlation with age demonstrates that during growth, the Achilles tendon accommodates its length to the heel valgus. A tight Achilles tendon is generally considered both the cause of flatfoot (congenital or a synchronized growing of bone and musculotendon unit) and the consequence of heel valgus positioning due to different etiologies $[33,43]$. This feature must be carefully evaluated because the need for elongation must be taken into account if surgical treatment is indicated. Objective clinical measurements, i.e., heel valgus and ankle-foot ROM, are necessary to quantify deformities useful for diagnosis and possibly to assess outcomes after treatment. Functional assessment by specific tests should be included in the examination, as evidence exists that morphology and function are not necessarily related. A systematic clinical approach to assess children with flexible flatfoot should always be recommended for the correct diagnosis of non-physiological flexible flatfoot and the associated treatment management based on symptoms, functional limitation, and foot dysfunction. There is still a paucity of information in quantifying Ankle Joint dorsiflexion. An inappropriate measurement using an in appropriate technique could have important repercussions. Wrong techniques for measurement and the use of poorly-validated instruments may provide a misdiagnosis from which wrong treatment modalities could ensue.

\section{References}

1. Donatelli R (1990) Biomechanics of the Foot and Ankle. Pa: FA Davis Co, Philadelphia, Pennsylvania, USA.

2. Leardini A, O'Connor J, Catani F, Giannini, S (1999) Kinematics of the human ankle complex in passive flexion: a single degree of freedom system. J Biomech 32 (2): 111-118.

3. Root ML, Orien WP, Weed JH (1977) Normal and Abnormal Function of the Foot. Vol 2, Clinical Biomechanics Corporation, Los Angeles, USA.

4. Hamel AJ, Sharkey NA, Buczek FL, Michelson J (2004) Relative motions of the tibia, talus, and calcaneus during the stance phase of gait: a cadaver study. Gait Posture 20(2): 147-153.

5. Leardini A, O'Connor JJ, Catani F, Martelli S, Giannini S (1998) The kinematics of the ankle in the sagittal plane. $11^{\text {th }}$ Conference of the ESB, Toulouse, France.

6. Gajdosik RL, Vander Linden DW, Williams AK (1999) Concentric isokinetic torque characteristics of the calf muscles of active women aged 20 to 84 years. J Orthop Sports Phys Ther 29(3): 181-190.

7. Gajdosik DH, Cooper L, Daniel D (1980) The role of the ankle plantar flexors in normal walking. J Bone Joint Surg Am 62(3): 354 -363.

8. Horak FB, Henry SM, Shumway-Cook A (1997) Postural perturbations: new insights for treatment of balance disorders. Phys Ther 77(5): $517-$ 533.

9. Sutherland DH, Cooper L, Daniel D (1980) The role of the ankle plantar flexors in normal walking. J Bone Joint Surg Am 62(3): 354 -363.

10. Meinders M, Gitter A, Czerniecki JM (1998) The role of ankle plantar flexor muscle work during walking. Scand J Rehabil Med 30(1): 39-46.

11. Belli A, Kyolainen H, Komi PV (2002) Moment and power of lower limb joints in running. Int J Sports Med 23(2): 136-141.

12. Bezodis IN, Kervin DG, Salo AI (2008) Lower-limb mechanics during the support phase of maximum-velocity sprint running. Med Sci Sports Exerc 40(4): 707-715. 
13. Adrian MJ, Cooper JM (1995) Biomechanics of human movement. WCB Brown \& Benchmark, Madison, Wisconsin, USA, pp. 295-314.

14. Biewener AA, Farley CT, Roberts TJ, Temaner M (2004) Muscle mechanical advantage of human walking and running implications for energy cost. Journal of Applied Physiology 97(6): 2266-2274.

15. Williams KR (2000) The dynamics of running. In: Zatsiorsky V (Ed.) Biomechanics in sport performance enhancement and injury prevention. Blackwell Science, Oxford, UK, pp.161-83.

16. Cronin JB, Hensen KT (2005) Strength and power predictors of sports speed. J Strength Cond Res 19(2): 349-357.

17. Shih YF, Chen CY, Chen WY, Lin HC (2012) Lower extremity kinematics in children with and without flexible flatfoot: a comparative study. BMC Musculoskelet Disord 13(1): 13-31.

18. Vittore D, Patella V, Petrera M, Caizzi G, Ranieri M, et al. (2009) Extensor deficiency: first cause of childhood flexible flat foot. Orthopedics 32(1): 28.

19. Menz HB (2008) Foot Problems in Older People: Assessment and Management. Elsevier Churchill Livingstone, London, UK.

20. Bonnet WL, Baker DR (1946) Diagnosis of pes planus by x-ray. Radiology 46(1): 36-45

21. Riccio I, Gimigliano F, Gimigliano R, Porpora G, Iolascon G (2009) Rehabilitative treatment in flexible flatfoot: a perspective cohort study. Chir Organi Mov 93(3): 101-107.

22. El O, Akcali O, Kosay C, Kaner B, Arslan Y, et al. (2006) Flexible flatfoot and related factors in primary school children: a report of a screening study. Rheumatol Int 26(11): 1050-1053.

23. Pfeiffer M, Kotz R, Ledl T, Hauser G, Sluga M (2006) Prevalence of flat foot in preschool-aged children. Pediatrics 118(2): 634-639.

24. Lin CJ, Lai KA, Kuan TS, Chou YL (2001) Correlating factors and clinical significance of flexible flatfoot in preschool children. Journal of Pediatric Orthopaedics 21(3): 378-382.

25. Levinger P, Murley GS, Barton CJ, Cotchett MP, McSweeney SR, et al. (2010) A comparison of foot kinematics in people with normal and flat arched feet using the Oxford Foot Model. Gait Posture, 32(4): 519-523.

26. Tiberio D (1987) The effect of excessive subtalar joint pronation on patellofemoral mechanics: A theoretical model. J Orthop Sports Phys Ther 9(4): 160-165.

27. Tome J, Nawoczenski DA, Flemister A, Houck J (2006) Comparison of foot kinematics between subjects with posterior tibialis tendon dysfunction and healthy controls. J Orthop Sports Phys Ther 36(9): 635-644.

28. Donatelli RA, Hurlburt C, Conaway D, Pierre R (1988) Biomechanical foot orthotics: a retrospective study. J Orthop Sports Phys Ther 10(6): 205-212.

29. Smart GW, Taunton JE, Clement DB (1980) Achilles tendon disorders in runner-a review. Med Sci Sports Exerc 12(4): 231-243.

30. Highlander P, Sung W, Weil L (2011) Subtalar arthroereisis. Clinics in Podiatric Medicine And Surgery (28): 745-754.

31. Dennis KJ, Cooke RA, Valmassy RL, Weed JH (1985) Biplane Posting Elevator. A new method of rearfoot post application. J Am Podiatr Med Assoc 75(5): 272-274.

32. McCulloch MU, Brunt D, Vander Linden D (1993) The effect of foot orthotics and gait velocity on lower limb kinematics and temporal events of stance. J Orthop Sports Phys Ther 17(1): 2-10.

33. Barry RJ, Scranton PE (1983) Flat feet in children. Clinical Orthopaedic and Related Research 181(3): 68-75.

34. Bordelon RL (1983) Hypermobile flatfoot in children. Comprehension, evaluation, and treatment. Clin Orthop Relat Res 181: 7-14.

35. Rose GK, Welton CA, Marshall T (1985) The diagnosis of flat foot in the child. J Bone Joint Surg Br 67(1): 71-78.

36. Bokaie F, Nasseri N, Mazaheri H, Fakhari Z, Jalaee J (2010) Strengths of lower extremity muscles in females with patellofemoral pain syndrome. Journal of Semnan Medical Sciences University 12(1): 22-30.

37. Nakagawa TH, Moriya ET, Carlos, Dias CD, Serrao FV (2012) Frontal plane Biomechanics in males and females with and without patellofemoral pain. Med Sci Sports Exerc 44(9): 1747-1755.

38. Frontera WR, Hughes VA, Lutz KJ, Evans WJ (1991) A cross-sectional study of muscle strength and mass in 45 to 78-year-old men and women. J Appl Physiol 71(2): 644-650.

39. Harries UJ, Bassey EJ (1990) Torque-velocity relationships for the knee extensors in women in their 3rd and 7th decades. European Journal of Applied Physiology 60(3): 187-190.

40. Kallman DA, Plato CC, Tobin JD (1990) The role of muscle loss in the age-related decline of grip strength: cross-sectional and longitudinal perspectives. J Gerontol 45(3): 82-88.

41. Bohannon RW (2007) Intertester reliability of hand-held dynamometry: a concise summary of published research. Perceptual and Motor Skills 88(1): 899-902.

42. Souza RB (2008) The influence of hip and femur kinematics on patellofemoral joint dysfunction. A dissertation presented to the faculty of the grauate school University of Southern California, USA.

43. Harris RI, Beath T (1948) Hypermobile flat-foot with short tendo achillis. J Bone Joint Surg Am 30(1): 116-140. 